\title{
Copolímeros de Estireno-Divinilbenzeno para Aplicação em Cromatografia de Exclusão por Tamanho
}

\author{
Márcia Angelica F.S. Neves, Marcos L. Dias e Fernanda M.B. Coutinho
}

\begin{abstract}
Resumo: Copolímeros de estireno-divinilbenzeno para a aplicação em cromatografia de exclusão por tamanho foram sintetizados através de polimerização em suspensão aquosa modificada pela presença de diluentes. $\mathrm{Na}$ síntese dos copolímeros foram variados os seguintes parâmetros reacionais: tipo de diluente, grau de diluição e teor de divinilbenzeno. Os copolímeros obtidos como partículas esféricas com tamanho médio em torno de $10 \mu \mathrm{m}$ foram caracterizados quanto à porosidade no estado seco e às propriedades de inchamento. Os copolímeros foram utilizados como material de empacotamento de colunas para cromatografia de exclusão por tamanho (SEC). O aumento do grau de diluição na síntese do copolímero aumentou o limite de exclusão da cromatografia, porém a redução do poder solvatante do diluente teve um efeito mais pronunciado sobre esse parâmetro.
\end{abstract}

Palavras-chave: Copolímeros de estireno-divinilbenzeno, propriedades de inchamento, cromatografia de exclusão por tamanho.

\section{Introdução}

Cromatografia de exclusão por tamanho (SEC) utiliza uma coluna empacotada com material poroso que separa moléculas de acordo com seu tamanho molecular efetivo em solução ${ }^{1-3}$. Esse tamanho, ou seja, o volume hidrodinâmico que a molécula ocupa em solução é dependente das características moleculares do polímero e do solvente utilizado a uma determinada temperatura.

O peso molecular e a distribuição de peso molecular são as características mais importantes de um polímero, pois suas propriedades mecânicas são fortemente influenciadas por esses parâmetros ${ }^{4}$. A determinação do peso molecular e de sua distribuição pode ser conseguida de forma bem rápida e fácil através de SEC.

Os materiais utilizados no empacotamento das colunas de SEC são partículas esféricas com porosidade permanente (estado seco) ou que apresentam porosidade quando inchadas por um solvente. Esses materiais podem ser substâncias orgânicas ou inorgânicas com uma estrutura tridimensional. Entre esses destacam-se os copolímeros de estirenodivinilbenzeno na forma de partículas esféricas ${ }^{1,3,5}$.

Através da polimerização em suspensão convencional é possível obter partículas esféricas, porém com tamanho relativamente grande e com uma larga distribuição de tamanhos de partícula para serem aplicados em SEC. Em SEC, o tamanho de partícula do material de empacotamento é um dos fatores mais importantes para uma boa separação. Partículas gran- 
des e com uma larga distribuição de tamanhos limita a resolução da coluna. Por outro lado, a presença de partículas muito pequenas reduz a permeabilidade da coluna, sendo necessária a aplicação de uma alta pressão para se obter uma vazão adequada de escoamento $^{6,7}$.

Para se obter copolímeros com uma faixa de tamanhos de partícula adequada para aplicação em SEC, o método de síntese indicado é uma modificação da polimerização em suspensão ${ }^{5,8}$. Nesse método a mistura reacional é submetida a altíssima velocidade de agitação numa etapa prévia à polimerização, para se obter gotículas de monômero dispersas na fase aquosa no tamanho adequado.

A estrutura porosa e as propriedades de inchamento dos copolímeros utilizados nas colunas de SEC são a base para o processo de separação de moléculas. Essas características são governadas pelo tipo de diluente, pelo grau de diluição dos monômeros e pelo teor de agente de reticulação utilizado em sua síntese $^{9}$. O tamanho dos poros do copolímero determina a faixa de tamanho molecular na qual ocorre a separação de moléculas ${ }^{1}$.

A porosidade dos copolímeros de estirenodivinilbenzeno é produzida através da polimerização dos monômeros em presença de diluentes, também denominados agentes formadores de poros. Esses agentes podem ser classificados em três categorias: diluentes solvatantes, diluentes não-solvatantes ou polímeros lineares ${ }^{9}$. Os diluentes são classificados em solvatantes ou não-solvatantes de acordo com a sua afinidade termodinâmica pelo copolímero ${ }^{10,11}$. A adição de uma mistura de dois tipos de diluentes ao meio de polimerização leva a obtenção de copolímeros com morfologias diferentes das obtidas com os diluentes puros.

Segundo Kun e Kunin ${ }^{12}$ a formação da estrutura porosa dos copolímeros pode ser descrita como um processo em três estágios. No primeiro estágio, o polímero formado é constituído de cadeias nucleares com grupos vinílicos pendentes. Com o prosseguimento da reação são formados os núcleos poliméricos que são microgéis reticulados intramolecularmente. Em função da temperatura, da concentração do agente de reticulação e do tipo e concentração do diluente ocorre uma separação de fases que leva a uma fase rica em copolímero e outra rica em diluente. A uma determinada conversão de monômeros ocorre a formação de microesferas que são o resultado da aglomeração dos núcleos poliméricos. Num segundo estágio, ocorre a formação da estrutura porosa, resultante da união das microesferas à medida que a polimerização continua e por fim no terceiro estágio, a estrutura porosa é concluída pela eliminação do diluente, por aquecimento.

As variações no tamanho dos poros pelo inchamento das partículas em diferentes solventes devem ser avaliadas para a aplicação em SEC, visto ser esta técnica realizada em presença de solventes ${ }^{6}$.

Este trabalho descreve a síntese de copolímeros de estireno-divinilbenzeno, sua caracterização morfológica e o seu desempenho como material de empacotamento em colunas para SEC.

\section{Experimental}

\section{Purificação dos reagentes e condições de síntese}

Estireno e divinilbenzeno (agente de reticulação) foram destilados a pressão reduzida. O percentual de divinilbenzeno utilizado nas sínteses foi expresso em relação ao número de moles de estireno. O iniciador, 2,2'-azo-bis-isobutironitrila (AIBN), foi recristalizado de solução metanólica. A fase orgânica da polimerização foi composta de $1 \%$ de AIBN em relação ao número total de moles de monômeros. Os diluentes, tolueno e heptano, foram utilizados como recebidos e suas quantidades foram expressas em relação ao volume total de monômeros. Poli(álcool vinílico) $88 \%$ hidrolizado foi utilizado como agente de suspensão a $0,5 \%(\mathrm{p} / \mathrm{p})$ em relação à água. A fase aquosa foi composta de água e agente de suspensão, e a orgânica de monômeros, iniciador e diluentes. A razão fase aquosa/ fase orgânica foi de 4/1 (v/v) para todas as reações.

Os solventes acetona, clorofórmio e metanol foram apenas destilados.

\section{Copolimerização}

Os copolímeros foram sintetizados através da polimerização em suspensão aquosa modificada. A mistura fase aquosa/fase orgânica foi adicionada a balão de três bocas de $1000 \mathrm{ml}$ de capacidade equipado com um dispersor e um borbulhador de nitrogênio. O conjunto foi colocado em banho de água/ gelo e submetido a uma alta velocidade de agitação por um tempo pré-determinado para a formação das gotas monoméricas no tamanho desejado. 
Após a dispersão da fase orgânica, o dispersor foi retirado do balão e foram adaptados agitador mecânico, condensador de refluxo e selo de mercúrio. A mistura reacional foi então aquecida a $70^{\circ} \mathrm{C}$ em banho termoestatizado, sob agitação de $400 \mathrm{rpm}$ por 24 horas.

\section{Purificação}

Após 24 horas de reação, as pérolas de copolímero resultantes foram separadas por filtração a pressão reduzida e lavadas exaustivamente com água destilada, água destilada quente e acetona. E finalmente lavadas com metanol e secas em estufa com circulação forçada de ar, a $50^{\circ} \mathrm{C}$, por 48 horas.

\section{Caracterização}

O tamanho das partículas foi determinado através de espalhamento de luz. O equipamento utilizado foi um Malvern, 3600 tipo E, com fonte de luz laser hélio-neônio de comprimento de onda de 633 nm e uma potência de $25 \mathrm{~mW}^{13-14}$.

A estrutura porosa dos copolímeros no estado seco foi avaliada através da determinação do volume de poros e da área especifica por adsorção de nitrogênio utilizando o equipamento ASAP da Micromeritics, modelo $2200 \mathrm{~A}$, seguindo os métodos BJH e BET, respectivamente ${ }^{15-16}$. O diâmetro médio de poros foi obtido pela relação entre o volume de poros e a área específica ${ }^{16}$.

As propriedades de inchamento foram avaliadas através de método gravimétrico em tolueno (bom solvente) e em heptano (mau solvente) pelo método de centrifugação ${ }^{17}$.

\section{Empacotamento das colunas cromatográficas}

Os copolímeros de estireno-divinilbenzeno foram empacotados em colunas de aço inoxidável $(7,8 \mathrm{~mm}$ x $30 \mathrm{~cm}$ ), após passagem em peneira de 200 mesh para a retirada de aglomerados. Uma suspensão a $10 \%$ $(\mathrm{p} / \mathrm{v})$ do copolímero em clorofórmio foi preparada e deixada em repouso por uma noite para o inchamento das pérolas. As colunas foram empacotadas usando clorofórmio como eluente, pela técnica de lama. A pressão final de empacotamento foi de aproximadamente $90 \mathrm{~kg} / \mathrm{cm}^{2}$. Terminado o empacotamento, o clorofórmio foi eluído a $1 \mathrm{ml} / \mathrm{min}$ até a estabilização da pressão. Este valor de pressão é o valor de operação da coluna cromatográfica, ou seja, a pressão quan- do são injetadas soluções-padrão a $1 \mathrm{ml} / \mathrm{min}$ na coluna cromatográfica.

\section{Avaliação das colunas cromatográficas}

A avaliação das colunas cromatográficas foi realizada em sistema de cromatografia constituído de refratômetro diferencial e bomba para abastecer a coluna com solvente na vazão estipulada.

Para cada coluna empacotada foram injetadas soluções-padrão de poliestireno numa faixa de peso molecular de 500 a $1,30 \times 10^{6}$, usando clorofórmio como eluente. A partir dos resultados de volume eluído dos padrões injetados foram construídas as curvas de calibração de logarítmo do peso molecular $(\log (\mathrm{Mw})$ versus volume eluído. O limite de exclusão de cada coluna cromatográfica, que corresponde ao peso molecular a partir do qual todas as moléculas analisadas percorreram somente o volume interpartículas, foi obtido através da interseção das retas vertical e inclinada da curva de calibração.

\section{Resultados e Discussão}

Os copolímeros sintetizados com tolueno puro e com altos teores de divinilbenzeno (Tabela 1) não apresentaram porosidade no estado seco, ou seja, os valores de área específica e o volume de poros não foram mensuráveis para esses copolímeros.

Tabela 1. Características dos copolímeros de estireno-divinilbenzeno sintetizados em tolueno e das respectivas colunas cromatográficas ${ }^{21,22}$

\begin{tabular}{|c|c|c|c|c|c|c|}
\hline $\begin{array}{c}\text { Teor de } \\
\text { DVB } \\
(\%)\end{array}$ & $\begin{array}{c}\text { Grau de } \\
\text { diluição } \\
(\%)\end{array}$ & $\begin{array}{c}\mathrm{dp} \\
(\mathrm{mm})\end{array}$ & $\begin{array}{c}\mathrm{R}_{\mathrm{tol}} \\
\left(\mathrm{cm}^{3} / \mathrm{g}\right)\end{array}$ & $\begin{array}{c}\mathrm{R}_{\text {hep }} \\
\left(\mathrm{cm}^{3} / \mathrm{g}\right)\end{array}$ & $\mathrm{LE}$ & $\begin{array}{c}\mathrm{PO} \\
\left(\mathrm{kg} / \mathrm{cm}^{2}\right)\end{array}$ \\
\hline 60 & & 9,3 & 0,96 & 0,82 & 2800 & 29 \\
\hline 80 & 80 & 10,8 & 0,98 & 0,88 & 2800 & 20 \\
\hline \multirow[t]{2}{*}{100} & & 11,6 & 0,99 & 0,95 & 2800 & 13 \\
\hline & 80 & 9,3 & 0,96 & 0,82 & 2800 & 29 \\
\hline \multirow[t]{3}{*}{60} & 100 & 10,5 & 1,14 & 0,96 & 3900 & 38 \\
\hline & 120 & 9,9 & 1,34 & 1,18 & 7600 & 41 \\
\hline & 80 & 11,6 & 0,99 & 0,95 & 2800 & 13 \\
\hline \multirow[t]{2}{*}{100} & 100 & 12,4 & 1,22 & 1,15 & 9700 & 13 \\
\hline & 120 & 12,3 & 1,37 & 1,24 & 12500 & 15 \\
\hline
\end{tabular}

$\mathrm{DVB}=$ divinilbenzeno; $\mathrm{dp}=$ diâmetro médio de partícula $; \mathrm{R}_{\mathrm{tol}}=$ retenção de tolueno; $\mathrm{R}_{\text {hep }}=$ retenção de heptano; $\mathrm{LE}=$ limite de exclusão; $\mathrm{PO}=$ pressão de operação 
Em sistemas com diluente solvatante para se obter porosidade no estado seco são necessários altos graus de diluição e altos teores de divinilbenzeno. Contudo, para os copolímeros sintetizados com tolueno, apesar do alto teor de divinilbenzeno, a quantidade de diluente presente durante a polimerização não foi suficientemente alta para se obter polímeros porosos.

Em partículas porosas, os poros formados durante a polimerização são classificados em: microporos (<50 $\mathrm{A}$ ), mesoporos (50 -500 $\AA$ ) e macroporos (> $500 \AA)^{11}$. A polimerização em presença de diluente solvatante tende a gerar preferencialmente microporos e mesoporos. Porém, como as cadeias internucleares apresentam uma alta mobilidade em presença desses diluentes, esses poros formados no estado inchado podem colapsar parcialmente ou totalmente com a retirada do diluente ${ }^{18-19}$.

Como pode ser visto na Tabela 1, embora esses copolímeros não apresentassem porosidade no estado seco, apresentaram uma certa capacidade de retenção tanto de tolueno como de heptano. E como já foi discutido em trabalho anterior ${ }^{20}$, a retenção de um bom solvente, por exemplo tolueno, é considerada como o resultado de três contribuições: preenchimento dos poros fixos, expansão dos poros fixos e colapsados e inchamento dos núcleos poliméricos. Neste caso, como os copolímeros não apresentam poros fixos, a retenção de tolueno pode ser atribuída às duas últimas contribuições, isto é, inchamento dos núcleos poliméricos e expansão dos poros colapsados. Por outro lado, a retenção de um mau solvente (heptano), é o resultado de duas contribuições: preenchimento dos poros fixos e expansão dos poros fixos e colapsados. No caso destes copolímeros, a retenção de heptano pode ser atribuída apenas à expansão dos poros colapsados.

A Figura 1 mostra as curvas de calibração de colunas empacotadas com copolímeros de estirenodivinilbenzeno sintetizados em tolueno com $80 \%$ de diluição e com teor de divinilbenzeno variado. Os valores de limite de exclusão (LE) obtidos a partir dessas curvas são apresentados na Tabela 1. Observa-se que LE não foi alterado pelo aumento do teor de divinilbenzeno. Neste caso, o aumento do teor de divinilbenzeno somente aumentou a resistência mecânica das pérolas de copolímero, diminuindo a possibilidade de deformação causada pela alta pressão aplicada durante o empacotamento da coluna cromatográfica. Como pode ser visto na Figura 1, o

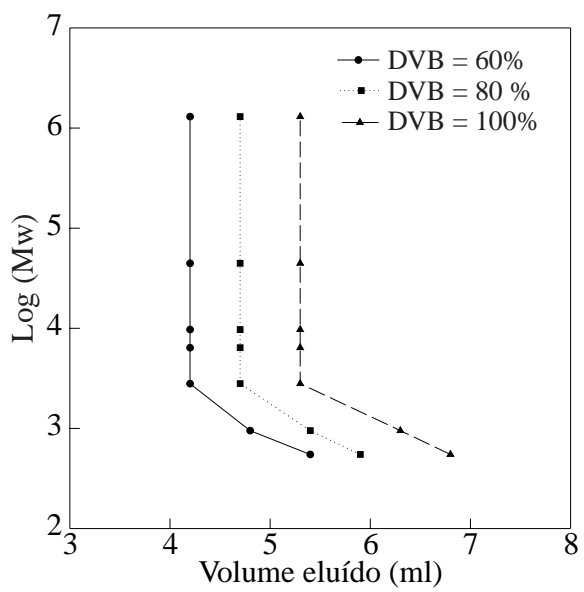

Figura 1. Curvas de calibração de colunas cromatográficas empacotadas com copolímeros de estireno-divinilbenzeno sintetizados em tolueno com $80 \%$ de diluição e com teor de divinilbenzeno variado

volume eluído de um mesmo padrão de poliestireno diminuiu com a diminuição do teor de divinilbenzeno usado na preparação do copolímero. $\mathrm{O}$ volume eluído no limite de exclusão corresponde ao volume intersticial ou interpartículas. Moléculas com peso molecular maior que o valor de LE percorrem somente o volume interpartículas. Através dos valores de pressão de operação das colunas, a uma vazão de $1,0 \mathrm{ml} / \mathrm{min}$ (Tabela 1), é possível também confirmar a ocorrência de maior deformação nas pérolas com a diminuição do teor de divinilbenzeno. Copolímeros com maiores teores de divinilbenzeno produzem colunas com menor pressão de operação.

Para as colunas empacotadas com copolímeros de estireno-divinilbenzeno sintetizados em tolueno com graus de diluição variados e com $60 \%$ e $100 \%$ de divinilbenzeno, as curvas de calibração mostram que o limite de exclusão aumentou com o aumento do grau de diluição (Figuras 2 e 3), sendo esses valores apresentados também na Tabela 1.

$\mathrm{O}$ aumento da diluição no meio reacional aumentou o volume de poros colapsados, que pode ser verificado pelo aumento de retenção de heptano (Tabela 1). Provavelmente este aumento do volume de poros foi o resultado do aumento do diâmetro médio de poros que como consequência levou a um aumento no limite de exclusão.

Observa-se também que o aumento da diluição deslocou a reta vertical, característica da exclusão total de moléculas com peso molecular médio ponderal maiores que o limite de exclusão, para valores de volume mais baixos. Isto sugere que o aumento da diluição durante a síntese gera copolímeros mais deformáveis sob pressão, quando inchados no solvente de empacotamento, resultando em menor volume intersticial. 


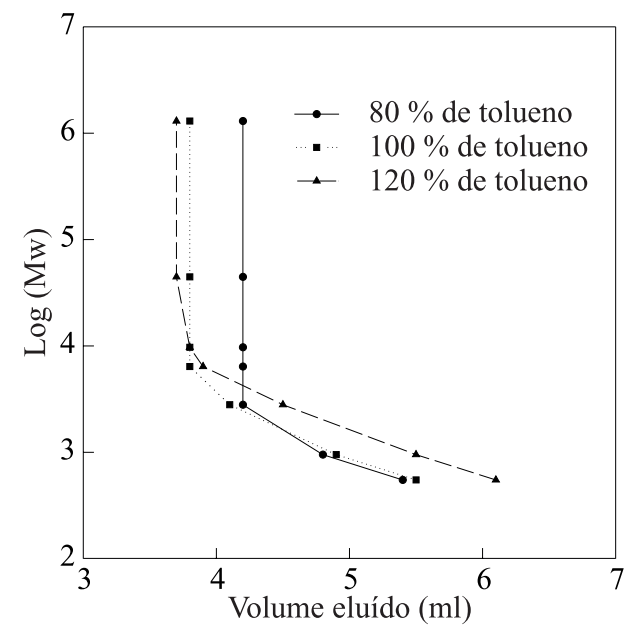

Figura 2. Curvas de calibração de colunas cromatográficas empacotadas com copolímeros de estireno-divinilbenzeno sintetizados em tolueno com graus de diluição variados e com $60 \%$ de divinilbenzeno

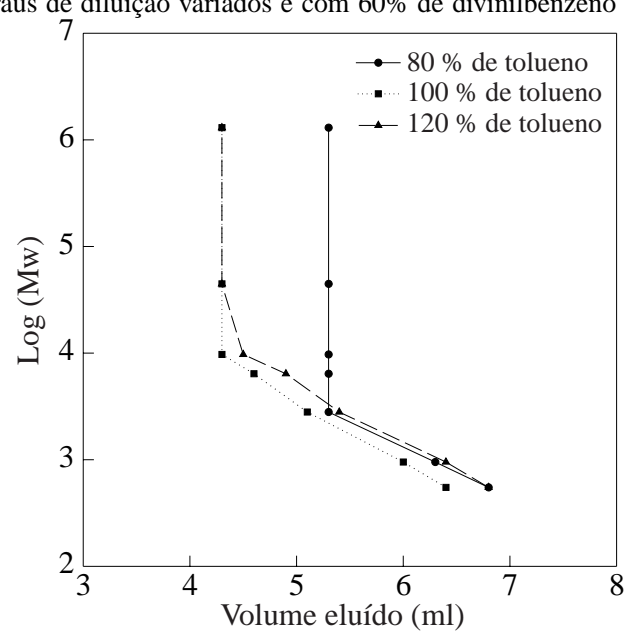

Figura 3. Curvas de calibração de colunas cromatográficas empacotadas com copolímeros de estireno-divinilbenzeno sintetizados em tolueno com graus de diluição variados e com $100 \%$ de divinilbenzeno

A pressão de operação, a uma vazão de 1,0 ml/ min para as colunas empacotadas com os copolímeros sintetizados com $100 \%$ de divinilbenzeno, foi mais baixa do que para as colunas empacotadas com copolímeros sintetizados com $60 \%$ de divinilbenzeno. Os copolímeros sintetizados com $100 \%$ de divinilbenzeno apresentam menor deformação, mantendo um maior volume intersticial.

As características dos copolímeros sintetizados com $100 \%$ de diluição e $60 \%$ de divinilbenzeno, utilizando uma mistura de diluente solvatante/ diluente não-solvatante, são mostradas na Tabela 2 . A redução do poder solvatante da mistura de diluentes, isto é, o aumento da proporção de heptano, produziu copolímeros com porosidade no estado seco. O volume de poros aumentou com o aumento do teor de heptano a partir da razão tolueno/heptano $=50 / 50$.

Com baixas proporções de heptano na mistura

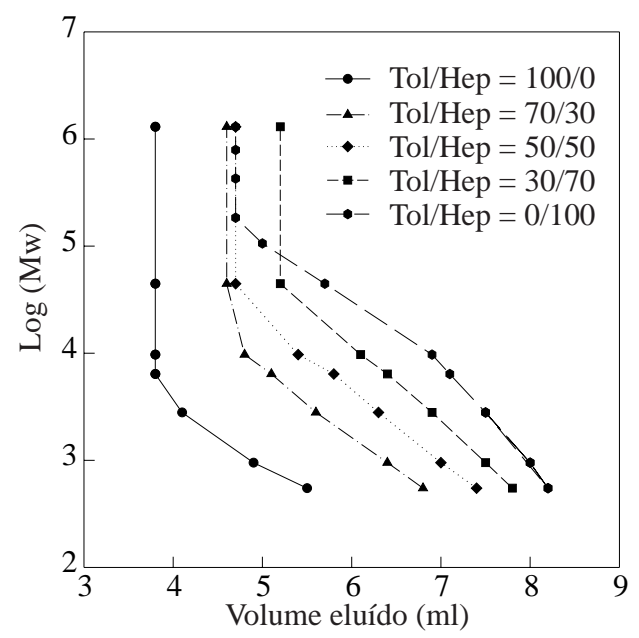

Figura 4. Curvas de calibração de colunas cromatográficas empacotadas com copolímeros de estireno-divinilbenzeno sintetizados em misturas tolueno/heptano a $100 \%$ de diluição e com $60 \%$ de divinilbenzeno

reacional, os valores de área específica e o volume de poros não foram mensuráveis, mostrando que para as razões tolueno/heptano 100/0 e 70/30, os copolímeros não apresentaram porosidade no estado seco.

As retenções de tolueno e heptano aumentaram à medida que foi aumentada a proporção de heptano na mistura usada como diluente durante a polimerização. Através da diferença entre os valores de retenção de tolueno e heptano, pode-se verificar que a capacidade de inchamento dos núcleos políméricos teve inicialmente um ligeiro decréscimo e em seguida permaneceu constante. Os copolímeros que apresentaram porosidade no estado seco não mostraram diferença no inchamento dos núcleos poliméricos. Para estes copolímeros a retenção de tolueno pode ser atribuída ao inchamento dos núcleos poliméricos, ao preenchimento dos poros fixos e à expansão dos poros fixos e colapsados e a retenção de heptano atribuída aos dois últimos fatores.

A Figura 4 mostra as curvas de calibração das colunas cromatográficas empacotadas com copolímeros de estireno-divinilbenzeno sintetizados em misturas tolueno/heptano, a $100 \%$ de diluição e com $60 \%$ de divinilbenzeno.

O volume eluído de cada padrão de poliestireno foi deslocado para valores maiores com o aumento da proporção de heptano na mistura diluente. Na presença de diluente não-solvatante, as cadeias nucleares e internucleares apresentam menor mobilidade devido ao seu maior emaranhamento formado durante a síntese. Essa menor mobilidade resulta em maior rigidez das partículas, diminuindo assim a deformação das pérolas do copolímero durante o processo de empacotamento das colunas cromatográficas. 
Tabela 2. Características dos copolímeros de estireno-divinilbenzeno sintetizados em tolueno/heptano (Tol/Hep) a $100 \%$ de diluição e $60 \%$ de divinilbenzeno e das respectivas colunas cromatográficas ${ }^{21,22}$

Tol/Hep
$(\%)$

$\begin{array}{lllllllll}100 / 0 & 10,5 & * & * & * & 1,14 & 0,96 & 3900 & 38\end{array}$

$\begin{array}{lllllllll}70 / 30 & 10,5 & * & * & * & 1,20 & 1,06 & 13100 & 23\end{array}$

$\begin{array}{lllllllll}50 / 50 & 12,9 & 56 & 0,120 & 85 & 1,22 & 1,12 & 27000 & 14\end{array}$

$\begin{array}{lllllllll}30 / 70 & 12,3 & 102 & 0,299 & 121 & 1,17 & 1,06 & 44800 & 13\end{array}$

$\begin{array}{lllllllll}0 / 100 & 12,3 & 92 & 0,391 & 170 & 1,36 & 1,26 & 149000 & 10\end{array}$

$\mathrm{dp}=$ diâmetro médio de partícula; $\mathrm{S}=$ área específica; $\mathrm{Vp}=$ volume de poros fixo; ' $\mathrm{D}=$ diâmetro médio de poros; $\mathrm{R}_{\text {tol }}=$ retenção de tolueno; $\mathrm{R}_{\text {hep }}=$ retenção de heptano; $\mathrm{LE}=$ limite de exclusão; $\mathrm{PO}=$ pressão de operação. * valores de área específica não-mensuráveis

A Tabela 2 mostra que o aumento da proporção de heptano gerou uma menor pressão de operação na coluna, que pode ser atribuído à menor deformação das pérolas do copolímero, produzindo maior volume interpartícula.

A Tabela 2 mostra também que o aumento da proporção de heptano provocou um grande aumento no limite de exclusão, devido provavelmente ao aumento do volume de poros com diâmetro médio maior.

\section{Conclusões}

Copolímeros de estireno-divinilbenzeno obtidos através da polimerização em suspensão modificada foram utilizados como material de empacotamento de colunas para cromatografia de exclusão por tamanho, mostrando que a variação da porosidade tem influência direta sobre o limite de exclusão. Para os copolímeros sintetizados com $80 \%$ de diluição com tolueno puro, o aumento do teor de divinilbenzeno aumentou a resistência mecânica dos copolímeros, sem alterar o limite de exclusão. Porém ao se manter constante o teor de divinilbenzeno e aumentar o grau de diluição, houve um aumento no limite de exclusão. Este trabalho mostrou que a afinidade entre o diluente e o copolímero exerce uma maior influência no limite de exclusão. Com o grau de diluição de $100 \%$ e teor de divinilbenzeno de $60 \%$, ao se utilizar heptano puro como diluente foi possível a obtenção de um limite de exclusão de 149000.

\section{Agradecimentos}

Os autores agradecem ao Programa de Apoio ao Desenvolvimento Científico e Tecnológico (PADCT/ CNPq), ao Conselho Nacional de Desenvolvimento Científico e Tecnológico (CNPq), a Nitriflex S.A., Indústria e Comércio e ao Centro de Pesquisas e Desenvolvimento da Petrobrás Leopoldo A. Miguez de Mello (CENPES/PETROBRÁS).

\section{Referências Bibliográficas}

1. Johnson J.F.; "Chromatography" em H.F. Mark, N.M. Bikales, C.G. Overberger, G. Menges; "Encyclopedia of Polymer Science and Engineering", Vol. 3, John Wiley \& Sons, New York, (1986).

2. Mickey C.D.; "Separation Technology. I. Chromatography"; Chemical Principles Revisited, 58, 997 (1981).

3. Glöckner G.; "Polymer Characterization by Liquid Chromatography" em Journal of Chromatography Library, Vol. 34, Elsevier Science Publishers, New York (1987).

4. Boletim Water Associates; USA, 1975.

5. Tanaka Y.and Takeda J.; "Gel permeation chromatographic packing and process for producting same utilizing suspension polymerization“, Patente Americana, ${ }^{\circ}$ 4.338.404 (1982).

6. Ellingsen T., Ugelstad J., Kulin L. and Flopin P.; "Monosized polymer particles in size-exclusion chromatography"; J. Chromatogr., 514, 1 (1990).

7. Ellingsen T., Aune O., Ugelstad J. and Hagen S.; "Monosized stationary phases for chromatography"; J. Chromatogr., 535, 147 (1990).

8. Kamiyama M., Koyama K., Matsuda H. and Sano Y.; "Micron-sized polymeric microsphere by suspension polymerization"; J.Appl. Polym. Sci., 50, 107 (1993). 
9. Poinescu I.C., Vlad C., Carpov A. and Ioanid A.; "On the structure of macroreticular styrene divinylbenzene copolymers"; Angew. Makromol. Chem., 156, 105 (1988).

10. Poinescu I.C., Vlad C. and Beldie C.; "Styrenedivinylbenzene copolymers: influence of the diluent on network porosity"; J. Appl. Polym. Sci., 29, 23 (1984).

11. Sederel W.L. and De Jong G.J.; "Styrenedivinylbenzene copolymers. Construction of porosity in styrene divinylbenzene matrices"; J. Appl. Polym. Sci., 17, 2835 (1973).

12. Kun K.A. and Kunin R.; "Macroreticular resins. III. Formation of macroreticular styrenedivinylbenzene copolymers"; J. Polym. Sci., 6, 2689 (1968).

13. Washington C.; "Particle size analysis in pharmaceutics and other industries"; Ellis Horwood Limited, New York, 1992.

14. Louvisse A.M.T.; "Caracterização de sistemas emulsionados através da técnica de espalhamento de luz"; Relatório do CENPES, nov/94.

15. Allen T.; "Particle size measurement"; Chapman abd Hall, $4^{\text {th }}$ ed., London, 1990.

16. Gregg S.J. and Sing K.S.W.; Adsorption, Surface
Area and Porosity", Academic Press Inc., $2^{\text {th }}$ ed., New York, 1982.

17. Lloyd W.G. and Alfrey T. Jr.; "Network polymers II - Experimental study of swelling"; J. Polym. Sci., 62,301 (1962).

18. Bacquet M., Lemaguer D. and Caze C.; "Porous texture and bromine distribution in porous styrene-bromostyrene-divinylbenzene terpolymers"; Eur Polym. J., 24, 533 (1988).

19. Okay O.; "Heterogeneous styrene-divinylbenzene copolymers stability conditions of the porous structure"; J. Appl. Polym. Sci., 31, 5533 (1986).

20. Rabelo D.; "Formação da estrutura porosa em copolímeros à base de estireno e divinilbenzeno", Tese de Doutorado, Universidade Federal do Rio de Janeiro, Brasil, 1993.

21. Coutinho F.M.B., Neves M.A.F.S. and Dias M.L.; "Porous structure and swelling properties of styrene-divinylbenzene copolymers for size exclusion chromatography",. J. Appl.Polym. Sci., aceito para publicação.

22. Neves M.A.F.S.; "Síntese, caracterização e avaliação em cromatografia de exclusão por tamanho de copolímeros de estirenodivinilbenzeno", Tese de Mestrado, Universidade Federal do Rio de Janeiro, Brasil, 1996. 